\title{
Genomic analysis of a newly isolated of Japanese encephalitis virus strain, CQ11-66, from a pediatric patient in China
}

Li-Juan Xu $u^{1,2,3,4}$, Ruixi Liu' ${ }^{1,2,3,4}$, Sheng Ye ${ }^{5}$, Hua Ling ${ }^{5}$ and Chao-Min Zhu ${ }^{1 *}$

\begin{abstract}
Background: Japanese encephalitis virus (JEV) is one of the major causative agents of viral encephalitis in East Asia, Southeast Asia and Australia. However, no clinical JEV strain has yet been isolated from JE patients in Chongqing, China. In this study, we report the genomic analysis of a new JEV strain, CQ11-66, isolated from a pediatric patient in Chongqing, China.

Findings: Virus isolation was carried out in BHK-21 cells. Nested PCR was used to detect and isolate the JEV strain, and computer analysis of phylogenetic relationships, nucleic acid homology studies and deduction of the amino acid sequence were conducted using ClustalX (1.8) and Mega5 software. The JEV strain CQ11-66 was isolated from patient cerebrospinal fluid. The sequenced genome of CQ11-66 was 10,863 nucleotides in length, whereas other strains, such as SX09S-01, contain 10,965 nucleotides. Sequence comparison of the CQ11-66 polyprotein open reading frame (ORF) with those of 21 other JEV strains revealed that the nucleotide sequence divergence ranged from $1.68 \%$ to $18.46 \%$. Sequence analysis of the full-length CQ11-66 E gene sequence with those of 30 other JEV isolates also identified nucleotide divergence, ranging from 1.69\% to $18.74 \%$. Phylogenetic analyses indicated that the CQ11-66 strain belonged to genotype III.
\end{abstract}

Conclusions: JEV genotype III still circulates in Chongqing and it is therefore important for active surveillance of JEV genotype III to be conducted in the pediatric population.

Keywords: Japanese encephalitis virus, Genomic analysis, CQ11-66 strain

\section{Findings}

Japanese encephalitis virus (JEV) is the most important causes of epidemic encephalitis in Southeast Asia and Western Pacific regions, with an estimated 35,000 to 50,000 cases each year, and approximately 1-3 of every $1000 \mathrm{JEV}$ infections resulting in severe disease [1]. JEV is a small, enveloped virus with a single-stranded, positive-sense RNA genome of approximately $11,000 \mathrm{nt}$. Its ORF is translated into a large polyprotein that includes three structural proteins $(\mathrm{C}$, prM and $\mathrm{E})$ and seven non-structural proteins (NS1, NS2A, NS2B, NS3, NS4A, NS4B and NS5) [2]. Since the first JEV isolate was reported in 1949,

\footnotetext{
*Correspondence: boybvip@126.com

'Department of Infectious diseases and Gastroenterology, Children's Hospital of Chongqing Medical University, No. 136 Zhongshan Er Road, Yuzhong District, Chongqing 400014, PR China

Full list of author information is available at the end of the article
}

JE epidemics have occurred in China, and Chongqing is listed as the region of highest incidence. However, no clinical JEV strain has been isolated from human cerebrospinal fluid (CSF), serum or brain tissue of fatal cases in Chongqing; thus, the molecular characteristics and genetic diversity of clinical JEV strains remain unknown.

In this study, acute serum and CSF specimens were collected from patients who were clinically diagnosed with Japanese encephalitis (JE) during July to October in 2011 and hospitalized in the Children's Hospital of Chongqing Medical University. Serum specimens were diluted in minimal essential medium at a ratio of 1 to 5 , pretreated with $100 \mathrm{U} \mathrm{ml}^{-1}$ penicillin and streptomycin and placed for at least four hours at $4^{\circ} \mathrm{C}$. CSF specimens were incubated directly. A monolayer of BHK-21 cells was grown to $90 \%$ confluence and incubated with either CSF or diluted serum at $37^{\circ} \mathrm{C}$. Once 
cytopathic effects (CPE) were observed in a culture, viruses were harvested from the culture medium by centrifugation at $10,000 \mathrm{rpm}$ for $10 \mathrm{~min}$. Viral RNA was extracted from the supernatant $(140 \mu \mathrm{L})$ of infected BHK-21 cells cultures using the QIAamp ${ }^{\circledR}$ Viral RNA kit (QIAGEN; USA). RNA was reversetranscribed using a random primer and amplified with a Go Tag $^{\circledR}$ Hot Start Polymerase kit (Promega; USA). The full-length genome was amplified by polymerase chain reaction (PCR) with TaKaRa LA Taq polymerase (TaKaRa; China) using seven pairs of primers (Table 1). The PCR reaction conditions were as follows: $3 \mathrm{~min}$ of cDNA denaturation at $94^{\circ} \mathrm{C}$, followed by 30 cycles of $94^{\circ} \mathrm{C}$ denaturation for $30 \mathrm{sec}, 55^{\circ} \mathrm{C}$ primer annealing for $30 \mathrm{sec}$, and $72^{\circ} \mathrm{C}$ primer extension for $1 \mathrm{~min}$. Amplified products were examined by agarose gel electrophoresis (1\%), purified with a Takara MiniBEST Agarose Gel DNA Extraction Kit Ver 3.0 (TaKaRa; China) and sent to TaKaRa for commercial sequencing. The full-length genome of the strains was compiled using the SeqMan program in the Lasergene software package (DNASTAR). The percentage similarities between aligned nucleotide or amino acid sequences were calculated using MEGA 5 software. Phylogenetic analysis was performed by the neighborjoining (NJ) method using MEGA5 software. For the previously published JEV strain sequences, the host background, year of isolation, geographic origin and GenBank accession number are listed in Table 2. Multiple sequence alignments and the $\mathrm{NJ}$ tree were generated by ClustalX (1.8). The genomic sequence of 21 strains and the $\mathrm{E}$ gene sequence of 30 strains were employed in the generation of the phylogenetic trees. The bootstrap probabilities of each node were calculated using 100 replicates.

Table 1 Primers for nucleic acid amplification assays

\begin{tabular}{lcc}
\hline Name & \multicolumn{1}{c}{$\mathbf{5}^{\prime}$ - $^{\prime}$} & Length \\
\hline PrimerF1 & AGTATCGTTGAGAAGAATCG & 20 \\
\hline PrimerF2 & TATGCTTTCCTGGCGGCGGTAC & 22 \\
\hline PrimerF3 & GAAGGGGAGACAAGCAGATCAA & 22 \\
\hline PrimerF4 & CTGCAAGAGAGGAAAAAGACCA & 22 \\
\hline PrimerF5 & GGAGGGGCAGAGTAGGCAGAAA & 22 \\
\hline PrimerF6 & CCGTTGGCTCGTGGAGAAAGGA & 22 \\
\hline PrimerF7 & TCAGCGGAGATGACTGTGTCGT & 22 \\
\hline PrimerR1 & CCTTCATTTCCTCCTCTTTGT & 22 \\
\hline PrimerR2 & TGAACGGCTTTCCTATGGAGT & 22 \\
\hline PrimerR3 & CAAACATCAATCCAACTGCCGA & 22 \\
\hline PrimerR4 & AGTCCATTGGGCATGTGTATGT & 22 \\
\hline PrimerR5 & TCTGCATGAGCATCGGTTCTTC & 22 \\
\hline PrimerR6 & AAATGGTAGAGCAGAAGGGAA & 22 \\
\hline PrimerR7 & TCTTCCTCACCACCAGCTACAT & 22 \\
\hline
\end{tabular}

In total, only one cell culture incubated with a patient CSF sample, named CQ11-66, tested positive by PCR, and none of the cell cultures incubated with patient serum samples tested positive. The genome sequence of CQ11-66 was 10,863 nucleotides in length, with an open reading frame (ORF) (GenBank: KC183732) of 10,296 nt coding for a polyprotein. When comparing its ORF with that of 21 other JEV strains isolated from different geographic regions or periods, high levels of similarity were observed, with nucleotide divergence ranging from $1.68 \%$ to $18.46 \%$, and amino acid divergence ranging from $0.32 \%$ to $4.89 \%$. A comparison of the CQ11-66 polyprotein ORF with that of SA14-14-2, the attenuated JEV vaccine strain currently widely used in China, discovered a total of 201 nucleotide differences (1.96\%) and 42 amino acid differences (1.23\%).

The nucleotide and amino acid sequences of the CQ11-66 strain $\mathrm{E}$ region were compared with those of other isolates available in GenBank. This analysis revealed that nucleotide divergence ranged from $1.62 \%$ to $18.74 \%$, while deduced amino acid divergence ranged from $1.01 \%$ to $5.13 \%$. Among these amino acid mutations, the E408 (Arg to Lys) variation was unique to CQ11-661. A comparison of the CQ11-66 strain E gene with that of SA14-14-2 also indicated $36 \mathrm{nu}-$ cleotide changes, resulting in 15 amino acid changes: E76 (Thr to Met), E107 (Phe to Leu), E138 (Lys to Glu), E176 (Val to Thr), E177 (Ala to Thr), E209 (Lys to Arg), E227 (Ser to Pro), E244 (Gly to Glu), E264 (His to Gln), E279 (Met to Lys), E306 (Glu to Gly), E315 (Val to Ala), E408 (Arg to Lys), E416 (Asp to Gly) and E439 (Asp to Gly). On the basis of the ORF gene sequences of 22 JEV isolates and the E gene sequences of $31 \mathrm{JEV}$ isolates, phylogenetic trees were constructed (shown in Figures 1 and 2). Both phylogenetic trees provided similar topology, and the analysis indicated that the CQ11-66 strain belonged to genotype III.

On the basis of 240 nucleotide of the C/prM gene, JEV strains were divided into five genotypes two decades ago $[3,4]$. However, the functional significance of the prM genetic variations remains to be established, and genetic relationships based on short sequences ( $<300 \mathrm{nt})$ should be required to take into account the biological significance and may be considered with caution $[5,6]$. Subsequently, the full-length E gene of JEV and its deduced protein sequence have been used as reliable phylogenetic markers, given that the $\mathrm{E}$ protein plays an important role in the JEV life cycle [7]. In China, many JEV strains belonging to genotype I and genotype III have been reported, and it was suggested by surveillance data that genotype I strains have been gradually replacing genotype III as the dominant strains in Asia. Due to limited sequence information regarding JEV isolates in Chongqing, the dominant genotype in one of the high-incidence regions in China remains unclear. In this study, phylogenetic analyses employing the ORF and E gene sequence of the CQ11-66 strain indicated it belonged to genotype III. 
Table 2 Bankground of Japanese encephalitis virus strains used in this study

\begin{tabular}{|c|c|c|c|c|c|c|}
\hline \multirow[t]{2}{*}{ Strain } & \multirow[t]{2}{*}{ Source } & \multirow[t]{2}{*}{ Genotype } & \multirow[t]{2}{*}{ Geographical location } & \multirow[t]{2}{*}{ Year } & \multicolumn{2}{|c|}{ GenBank accession no./reference } \\
\hline & & & & & ORF & E gene \\
\hline Beijing-1 & Human & III & China & 1948 & L48961 & L48961 \\
\hline $\mathrm{CH} 1392$ & Mosquito & III & Taiwan & 1990 & AF254452 & U44960.1 \\
\hline FU & Human & $\|$ & Australia & 1995 & AF217620 & L43565.1 \\
\hline GP78 & Human & III & India & 1978 & AF075723 & AF075723 \\
\hline SA14-14-2 & Vaccin strain & III & China & 1954 & AF315119.1 & AF315119.1 \\
\hline JaGAr01 & Mosquito & III & Japan & 1959 & AF069076 & AF069076 \\
\hline WTP & Mosquito & $\|$ & Malaysia & 1970 & HQ223286 & U70421 \\
\hline K94P05 & Mosquito & I & Korea & 1994 & AF04555 & U34929 \\
\hline JKT5441 & Mosquito & $\|$ & Indonesia & 1981 & AF045551 & U34929 \\
\hline JKT6468 & Mosquito & IV & Indonesia & 1981 & AY184212 & U70407 \\
\hline Ishikawa & Mosquito & I & Japan & 1998 & AB051292 & AB051292 \\
\hline Ling & Human & III & Taiwan & 1965 & L78128 & L78128 \\
\hline RP-9 & Mosquito & III & Taiwan & 1985 & AF014161 & AF014161 \\
\hline 47 & Human & III & China & 1950s & AY243827 & AY243827 \\
\hline SA14 & Mosquito & III & China & 1960 & U14163 & AY243850 \\
\hline K87P39 & Mosquito & III & Korea & 1987 & AY585243 & AY585243 \\
\hline P20778 & Human & III & India & 1958 & AF080251 & Z34096 \\
\hline $\mathrm{CH} 21955 \mathrm{~A}$ & Mosquito & III & Taiwan & 1994 & AF221500 & AF221500 \\
\hline ML11 & Vaccine & III & Japan & 1981 & AY508812 & U70412 \\
\hline jaOArS982 & Mosquito & III & Japan & 1982 & M18370 & M18370 \\
\hline Nakayama & Human & III & Japan & 1935 & EF571853 & AF112297 \\
\hline JKT7003 & Mosquito & IV & Indonesia & 1981 & & U70408 \\
\hline Sagiyama & Mosquito & III & Japan & 1957 & & U70419 \\
\hline Kamiyama & Human & III & Japan & 1966 & & AB379813 \\
\hline K82P01 & Mosquito & III & Japan & 1982 & & U34926 \\
\hline 826309 & Human & III & India & 1982 & & Z34094 \\
\hline ThCMAr6793 & Mosquito & 1 & Thaliand & 1993 & & D45363 \\
\hline JKT1724 & Mosquito & III & Indonesia & 1979 & & U70404 \\
\hline $\mathrm{SH}-53$ & Mosquito & 1 & China & 2001 & & AY555757 \\
\hline PhAn1242 & Pig & III & Philippines & 1984 & & U70417 \\
\hline
\end{tabular}




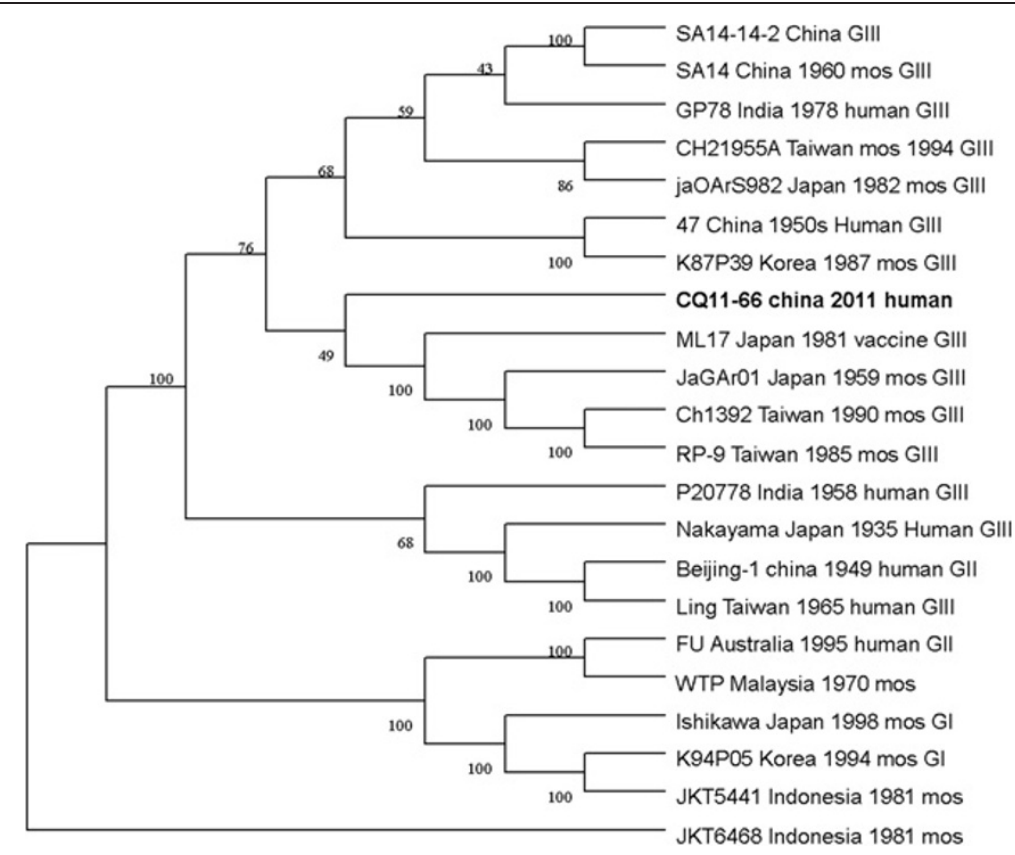

Figure 1 Phylogenetic tree constructed by the neighbor-joining method, based on the polyprotein ORFs of selected Japanese encephalitis virus strains. The CQ11-66 China 2011 human obtained in this study is shown in bold face.

The crystallographic structure of the E protein of the flavivirus tick-borne encephalitis virus revealed that the $\mathrm{E}$ protein consists of three domains. The difference in the $\mathrm{E}$ gene of JEV strains, particularly in domain III [8], may contribute to the diversity of neutralizing and antigenic properties [9]. Previous research has also indicated that mutations in domain III modulated virus binding and entry into host cells $[10,11]$. In this study, comparison of the E gene of CQ11-66 strain with the vaccine strain SA14-14-2 revealed 15 amino acid substitutions. Among these variations, the Glu to Lys alteration at position 138 is consistent with previous observations that the E138 mutation is associated with attenuation of the JEV strain and inhibits viral spread from cell to cell [12]. Other groups have also demonstrated that mutations of residues E49, E138, E306 and E389 of the E protein reduce the efficiency of viral binding to heparan sulphate residues on target cells [13]. In our results, a substitution (Met to Lys) was observed at the position E279, which may increase virulence in mice [14].

Genetic variation among JEV strains isolated from widely different time periods and geographical regions has been reported in many studies [13]. A previous study examining $46 \mathrm{JEV}$ strains found that those from a much wider geographic region and at certain time period were similar, but that genetic variation was present among strains from diverse regions or from different time periods in the same region. These observations suggested JEV is continuously evolving [15]. Meanwhile, Yun et al. [16] reported that the $\mathrm{E}$ gene sequences of the 10 Korean JEV strains, despite differences in their geographic distributions and the maximum five-year time span, showed remarkable genetic stability. Such stability in the JEV genome was also observed in strains from China and Japan $[17,18]$. In this study, phylogenetic analyses of the CQ11-66 ORF and the ORF of 21 other JEV strains isolated from several countries revealed the lowest nucleotide divergence and the lowest amino acid divergence with the JaGA01 strain. Meanwhile, phylogenetic analyses of its E gene and the E gene of 30 other JEV strains revealed the lowest nucleotide divergence and the lowest amino acid divergence with the JaGA01 strain.

In conclusion, we have isolated a JEV strain from a JE patient in Chongqing, China. Molecular analysis of the nucleotide and amino acid sequences indicated that CQ11-66 belonged to genotype III, and comparison of the ORF sequence and the E gene sequence with other strains from different regions at different periods revealed high homology.

\section{Ethics statement}

The study was performed after consultation with the patients or their guardians and after the receipt of written consent. The study-related information was used anonymously. The Institutional Review Board of the Children's hospital of Chongqing Medical University approved the research involving human materials.

\section{Competing interests}

The authors declare that they have no competing interests. 


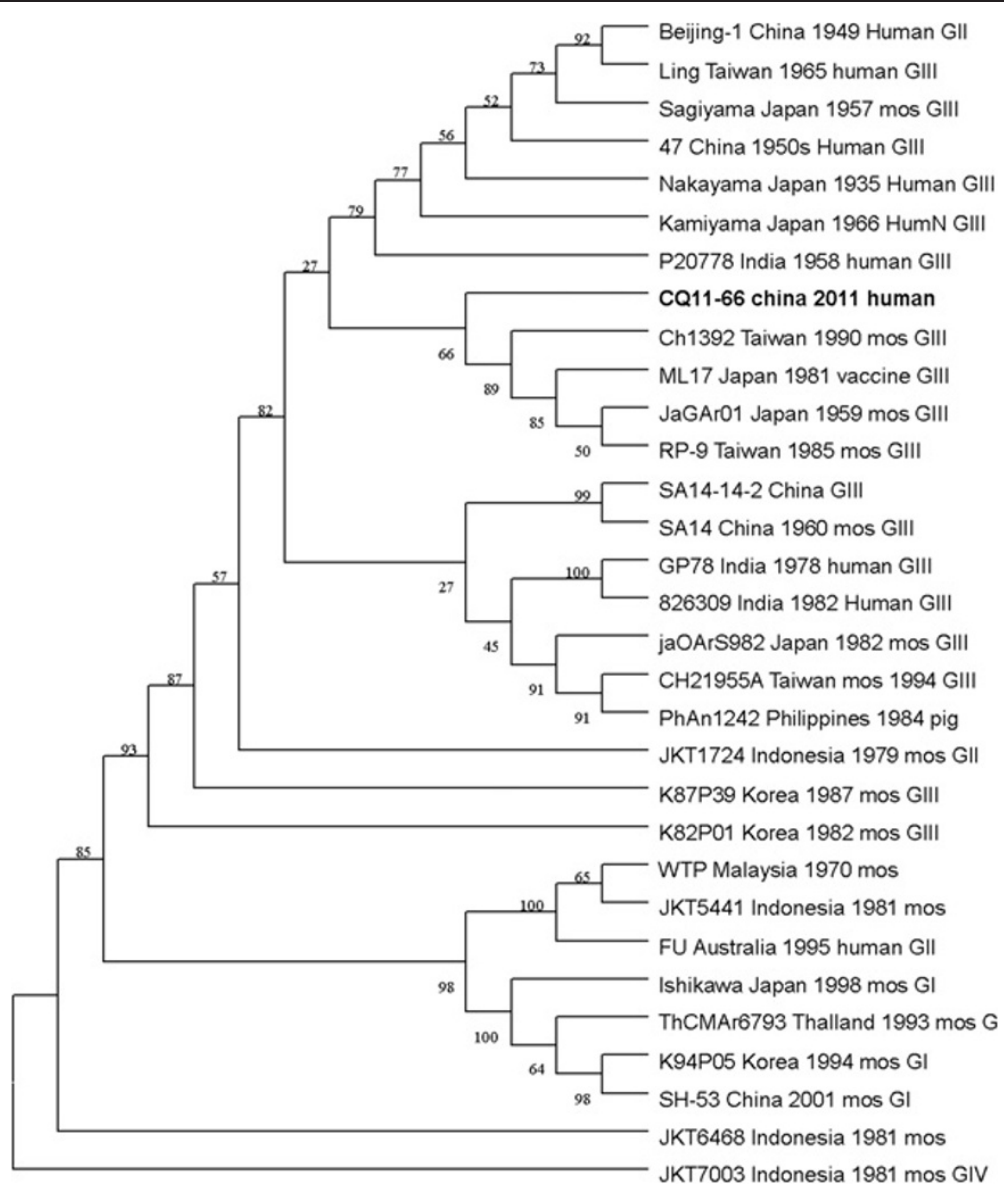

Figure 2 Phylogenetic tree constructed by the neighbor-joining method, based on the envelope (E) protein gene of selected Japanese encephalitis virus strains. The CQ11-66 China 2011 human obtained in this study is shown in bold face.

\section{Authors' contributions}

LX performed the experiments, prepared of the manuscript, collected the specimens and contributed to the data analysis. SY contributed to the preparation of the manuscript. CMZ and HL designed the study. All authors have read and approve the final manuscript.

\section{Acknowledgements}

We are grateful to Dr Yongjun Zhang from Fujian Center for Disease Control and Prevention for technical advice.

\section{Author details}

'Department of Infectious diseases and Gastroenterology, Children's Hospital of Chongqing Medical University, No. 136 Zhongshan Er Road, Yuzhong District, Chongqing 400014, PR China. ${ }^{2}$ Ministry of Education Key Laboratory of Child Development and Disorders, No. 136 Zhongshan Er Road, Yuzhong District, Chongqing 400014, China. ${ }^{3}$ Key Laboratory of Pediatrics in Chongqing,CSTC2009CA5002), No. 136 Zhongshan Er Road, Yuzhong District, Chongqing 400014, China. ${ }^{4}$ Chongqing International Science and Technology Cooperation Center for Child Development and Disorders, No 136 Zhongshan Er Road, Yuzhong District, Chongqing 400014, China.

${ }^{5}$ Chongqing Center for Disease Control and Prevention, Chongqing, China.

Received: 24 July 2012 Accepted: 22 March 2013

Published: 1 April 2013

\section{References}

1. Yun SI, Kim SY, Rice CM, Lee YM: Development and application of a reverse genetics system for Japanese encephalitis virus. JViro 2003, 77:6450-6465.
2. Lindenbach $B D$, Rice $C M$ : Flaviviridae:the viruses and their eplication. In Fields Virology. 4th edition. Edited by Knipe DM Howley PM. Philadelphia: Lippincott Willams and Wilkins; 2001:991-1041.

3. Ali A, Igarashi A: Antigenic and genetic variation among Japanese encephalitis virus strains belong to genotype I. Microbio Immunol 1997, 41:241-252.

4. Huong VT, Ha D, Deubel V: Genetic study of Japanese encephalitis viruses from Vietnam. AmJTrop Med Hyg 1993, 49:538-544.

5. $\mathrm{Ni} \mathrm{H}$, Barret ADT: Nucleotide and deduced amino acid sequence of the structural protein genes of Japanese encephalitis viruses from different geographical location. J Gen Virol 1995, 76:401-407.

6. Westaway EG, Block J: Taxonomy and evolutionary relationships of flavivirus. pp. 147-173. Walling Ford: CAB International; 1997.

7. Monath TP, Heinz FX: Flaviviruses,p.961-1034. In Fields virology. 3rd edition. Edited by Fields BN, Knipe DM, Howley PM. Philadephia, Pa: Lip- pincott-Raven; 1996.

8. Rey FA, Heinz FX, Mandl C, Kunz C, Harrison SC: The envelope glycoprotein from tick-borne encephalitis virus at 2 A resolution. Nature 1995, 375:291-298.

9. Gritsun TS, Holmes EC, Gould EA: Analysis of flavivirus envelope proteins reveals variable domains that reflect their antigenicity and may determine their pathogenesis. VirusRes 1995, 35:307-321.

10. Hung JJ, Hsieh MT, Young MJ, Kao CL, King CC, Chang W: An external loop region of domain III of denguevirus type 2 envelope protein is involved in serotype-specific binding to mosquito but not mammalian cells. J Virol 2004, 78:378-388.

11. Liu H, Chiou S-S, Chen W-J: Differential binding efficiency between the envelope protein of Japanese encephalitis virus variants and heparin sulfate on the cell surface. J Med Virol 2004, 72:618-624.

12. Zhao Z, Date T, Li Y, Kato T, Miyamoto M, Yasui K, Wakita T: Characterization of the E-138(Glu/Lys) mutation in Japanese encephalitis virus By using a stable, full-length, infectious CDNA clone. J Gen Virol 2005, 86:2209-2220. 
13. Mangada MN M, Takegami T: Molecular characterization of the Japanese encephalitis virus representative immunotype strain JaGAr01. Virus Res 1999, 59:101 \pm 112 .

14. Monath TP, Arroyo J, Levenbook I, Zhang ZX, Catalan J, Draper K, Guirakhoo F: Single mutation in the flavivirus envelope protein hinge region increases neurovirulence for mice and monkeys but decreases viscerotropism for monkeys: relevance to development and safety testing of live,attenuated vaccines. J Virol 2002, 76:1932-1943.

15. Williams DT, Wang LF, Daniels PW, Mackenzie JS: Molecular characterization of the first Australian isolate of Japanese encephalitis virus, the FU strain. J Gen Virol 2000, 81:2471-2480.

16. Yun SM, Cho JE, Ju YR: Molecular epidemiology of Japanese encephalitis virus circulating in South Korea,1983-2005. Viro J 2010, 7:127.

17. Wang HY, Takasaki T, Fu SH, Sun XH, Zhang HL, Wang ZX, Hao ZY, Zhang JK, Tang Q, Kotaki A, Tajima S, Liang XF, Yang WZ, Kurane I, Liang GD: Molecular epidemio-logical analysis of Japanese encephalitis virus in China. J Gen Virol 2007, 88:885-894

18. Nerome R, Tajima S, Takasaki T, Yoshida T, Kotaki A, Lim CK, Ito M, Sugiyama A, Yamauchi A, Yano T, Kameyama T, Morishita I, Kuwayama M, Ogawa T, Sahara K, Ikegaya A: Molecular epidemiological analyses of Japanese encephalitis virus isolates from swine in Japan from 2002 to 2004. J Gen Virol 2007, 88:2762-2768.

doi:10.1186/1743-422X-10-101

Cite this article as: Xu et al:: Genomic analysis of a newly isolated of Japanese encephalitis virus strain, CQ11-66, from a pediatric patient in China. Virology Journal 2013 10:101.

\section{Submit your next manuscript to BioMed Central and take full advantage of:}

- Convenient online submission

- Thorough peer review

- No space constraints or color figure charges

- Immediate publication on acceptance

- Inclusion in PubMed, CAS, Scopus and Google Scholar

- Research which is freely available for redistribution 